\title{
ЧО ЧЕЛОВЕК И ТРУД
}

\author{
Потравная Е.B.
}

\section{РЫНОК ТРУАА: ОСОБЕННОСТИ ПОВЕАЕНИЯ МОАОАЫХ СПЕЦИААИСТОВ НА ОСНОВЕ САМООЦЕНКИ СВОИХ КОМПЕТЕНЦИЙ}

\begin{abstract}
Аннотация. В статье рассматриваются особенности поведения и трудоустройства молодыхспециалистов на основе самооценки своих имеющихся компетенций. Предметом исследования выступает экономическое поведение на рынке труда, под которым понимается тип поведения, связанный с реализачией и развитием собственного человеческого капитала путем нахождения оптимального соотношения издержек и дохода. Аанный тип поведения подразумевает субъективное восприятие оплаты труда с учетом уровня реализачии человеческого капитала, мотивачионных установок, общекультурных и образовательных компетенций личности. Особое внимание уделяется анализу самооченки молодых соискателей на рынке труда. В качестве метода исследования используются сочиологические опросы студентов. Значимые компетенции сочиальных субъектов при выборе первой работы на рынке труда молодыми специалистами предлагается осуществлять на основе самооченки молодежи своих профессиональных и мичных качестве. В качестве таких очениваемых параметров предлагается рассматривать коммуникативные качества, владение иностранными языками, креативность, организаторские способности и др. Установлено, что проблема поведения современной молодежи на рынке труда проявляется в противоречии желаемого и реального поведения. Предлагается классификация основных факторов, влияющих на формирование молодежного рынка труда. Выявлено влияние экологических факторов, потребностей и интересов молодежи при выборе места будущей работы, наряду с такими факторами, как оплата труда, близость к месту работы, бренд компании и др.Определена специфика и основные тенденции развития молодежного рынка труда. Результаты исследования направлены на совершенствование деятельности вузов в
\end{abstract}


условиях перехода на новые образовательные стандарты с учетом компентностного подхода при подготовке бакалавров и магистров и формирование модели взаимодействия вуза, работодателя и специиалистов на рынке труда, которая отвечает современным требования экономики.

Ключевые слова: рынок труда, компетентностный подход, самооценка, трудоустройство, молодые специалисты, студенты, выпускники, работодатели, компетенции, экономическое поведение.

Abstract. This article reviews the peculiarities of behavior and employment of the young professionals based on the self-evaluation of the existing competencies. The subject of the research is the economic behavior on the job market, which means the type of behavior associated with the realization and development of personal human capital by finding the optimal ratio of expenses and income. Such type of behavior implies the subjective perception of wages with consideration of the level of realization of human capital, motivational orientations, as well as cultural and educational competencies of an individual. Special attention is given to the analysis of self-evaluation of the young applicants on the job market. Among the assessing parameters it is suggested to review the communicative skills, knowledge of foreign languages, creativeness, organizational abilities, etc. It is noticed that the issue of the behavior of the modern youth on the job market is manifested in the contradiction between the desired and the actual behavior. The author proposes classification of the main factors affecting the formation of the youth job market, as well as determines the influence of environmental factors, the needs and interests of the youth in choosing the places of future employment, alongside such factors as wages, location, brand of the company, and others. The results of this research are aimed at the improvement of the work of the higher educational facilities under the conditions of transition to the new educational standards, as well as at the creating the model of collaboration between the universities, employers, and specialists on the job market, which meets the modern economic demands.

Key words: Job market, Competent approach, Self-evaluation, Employment, Young professionals, Students, Graduates, Employers, Competencies, Economic behavior.

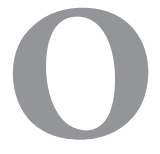

Ана из наиболее обсуждаемых, спорных и пропагандируемых тем современной действительности - профессиональное становление и занятость молодежи. Развитие общества Аиктует свои требования к образовательным стандартам современной России. Молодежь после окончания школы преАпочитает поступать в институт и очень часто только с целью получения высшего образования без привязки к конкретной профессиональной Аеятельности. Именно в контексте успешной профессионамьной социализации, определяющей понимание социацьной значимости своей профессии, происходит формирование эффективных стратегий поведения на рынке труаа.

В широком понимании молодежный рынок труаа преАстав яет собой систему социацьноэкономических взаимоотношений межАу моло-

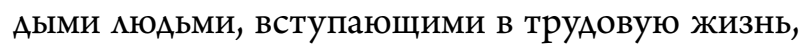
и работодатемями по поводу найма или проАажи рабочей силы с учетом уровня квалификации, знаний, умений и навыков [4]. Особую актуамьность исследование молодежных рынков труда приобретает в условиях перехода высших учебных заведений на новые образоватемьные станАарты, в рамках которых необходимо учитывать компетентностный поАхоА при ПоАГотовке бакалавров и магистров [2]. Разработанные компетенции по своей сути отвечают современным стандартам рынка труда, но такого вида изменения порожАают все больше разговоров как среАи работодателей, так и профессорско-преподаватемьского состава.

Особо значение имеет анализ поведения стуАентов и выпускников ВУЗов, которые выхоАят на рынок труаа в поиске своего первого места работы. Обычно, поведение выпускника на рын- 
Факторы, оказывающие вмияние на экономическое повеАение на рынке труАа

\begin{tabular}{|c|l|l|}
\hline $\begin{array}{c}\text { №№ } \\
\mathbf{n} / \mathbf{n}\end{array}$ & \multicolumn{1}{|c|}{ Группа факторов } & \multicolumn{1}{c|}{ Факторы } \\
\hline 1. & Экономические факторы & Соотношение издержек и выгод \\
\hline 2. & $\begin{array}{l}\text { Социально-демографиче- } \\
\text { ские факторы }\end{array}$ & $\begin{array}{l}\text { Численность население, динамика рождаемости (демографические ямы); } \\
\text { Пол и возраст; } \\
\text { Состав семьи; } \\
\text { Продолжительность жизни; } \\
\text { Динамика браков }\end{array}$ \\
\hline 3. & $\begin{array}{l}\text { Медико-биологические } \\
\text { факторы }\end{array}$ & $\begin{array}{l}\text { Установка на здоровый образ жизни; } \\
\text { Возможности организма; } \\
\text { Биологические ритмы; } \\
\text { Факторы психического развития личности }\end{array}$ \\
\hline 4. & Гендерные факторы & Мужское и женское восприятие работы \\
\hline 5. & Юридические факторы & Уровень правовой культуры общества \\
\hline 6. & Психологические факторы & Психические особенности личности \\
\hline 7. & Социальные факторы & $\begin{array}{l}\text { Уровень социализации индивида, уровень социальной стратификации, } \\
\text { физическое окружение, наследственные стереотипы, социальные и } \\
\text { моральные нормы общества }\end{array}$ \\
\hline 8. & $\begin{array}{l}\text { Факторы государственного } \\
\text { регулирования вопросов } \\
\text { занятости и рынка труда }\end{array}$ & $\begin{array}{l}\text { Уровень государственного регулирования рынка труда; } \\
\text { Государственная политика поддержки занятости; } \\
\text { Наличие гражданского общества, профсоюзов }\end{array}$ \\
\hline 9. & Экологические факторы & Уровень экологической культуры \\
\hline
\end{tabular}

Примечание: составлено автором.

ке труда базируется на его мичных и социальных установках, которые могут дополняются объективным уровнем профессиональной поАготовки. На такие установки могут оказывать влияние размичные факторы. Уровень влияние того или иного фактора будет всегАа разнится у кажАого соискателя, но выявление подобных закономерностей в поведение помогает повысить эффективность как системы подготовки специалистов, так и возможность реального трудоустройства выпускников. Совпадение возможностей и жеманий соискателя явмяется не только своего роАа условием его социального удовметворения от покучаемой работы, но рационального понимания своего собственного потенциака. На практике всяческие откионения от идеального типа повеАения порожАают новые концепции, связанные не только с психологическими особенностями мичности, но и с историческим развитием всего общества в целом [5].

В ходе исследования автором было предложено разработать классификацию факторов, которые имеют воздействие на становление и проявления поведения человека на рынке труда. Группы факторов преАставлены в хаотичном порядке, не основываясь на степени значимости.
Аля каждой конкретной социальной группы в большей ими меньшей степени будут иметь значения конкретные факторы из преАставленных групп, представлены в таблице 1.

Особое внимание по данным таблице стоит обратить на гендерные факторы. По данным Всемирного банка, около $40 \%$ мировой рабочей силы составцяют женщины. Несмотря на остающуюся тенденцию к Аискриминации женского труда, современная женщина - это полноправный субъект трудового процесса. Основная особенность в изучении гендерных подходов к пониманию и стратегии поиска работы заключается в том, что Аля женщины существуют Аве сферы труда: оплачивая работа и домашняя работа. И женщина, выходя на рынок труда Аля поиска работы, стремится найти такое место работы, которое будет отвечать ее требования к совмещению этих Авух отраслей.

В настоящее время возрастает система «земеных» офисов. Несколько тысяч российских преАприятий разработали и внеАрили систему экологического управмения на основе межАународных стандартов ИСО 14000. Примером в этом плане явцяются большие компании, Аавно зарекомендовавшие себя на рынке, например, 
$\mathrm{OAO}$ «Газпром». Степень узнаваемости Аанной компании велика как в России, так и за ее преАелами [5]. Как показывают исследования проведенные автором в 2014-2016 году, в которых принимали участие больше 1000 молодых специалистов из разных городов России. Многие компании слабо позиционируются как экомогически ответственные, что обусловлено такими факторами, как низкая кумьтура ведения бизнеса с учетом требований охраны окружающей среАы, недостаточное финансирование природоохранной деятельности, произвоАство недостаточно экологичной и энергетически эффективной продукции и Ар. И тем самым именно Аля молоАых специалистов экологический фактор не явмяется Аоминирующим.

Описывая молодежный рынок труда, необходимо отметить ряд зарубежных моделей, которые объясняют процесс взаимодействия выпускников и работодателей, в том числе и на российском рынке труда. Модель сигналов М. Спенса была опубликована в 1972 году. Стреммение работодателей до начала формальных труАовых отношений выявить производительность труда будущего сотрудника, заставмяет искать объективные данные о соискателе. За основу в Аанной теории обычно берется образование. Оно выступает в роли сигнала, который соискатель передает работодателю. Согласно Спенсу, Аиплом работника говорит о его производительности. Высокопроизводительным сотрудникам мегче получить образование, т.к. они затрачивают меньше усилий и тем самым уменьшают свои издержки. Особое значение данная модель приобретает дмя молодежного рынка труда. Именно Аля студентов, которые не имеют полноценного опыта работы, образование - их основное конкурентное преимущество. [10].

Похожие взгляды на проблему образования и в Аругих работах зарубежных социологов, в работах Комминза Рэндамл утвержАается, что стоимость мюбого вида образования зависит не от конкретного содержании, а все больше от полученного официального удостоверения, что позволяет выходить на рынок труаа. Рынки труда, основанные на принципе станАартизации образования (credentialism), не включают в себя требования по проверке опыта и навыков соискателей, а полученная бумажка об образовании имеет большую сику, чем твои практические навыки $[7,9]$.

В рамках западной социологии к определению экономического поведения на рынке труда Аобавляется роль профсоюзных организаций. Соискатель пытается найти сильного работоАателя, который сможет Аиктовать условия Амя рынка труда. Работодатели же наоборот пытаются уменьшить количество форм социальных поощрений аля своих сотруАников (социальные мьготы, рабочее время и т.А.). И в этом случае решающую роль играют профсоюзы [8].

В российской научной сфере сложились следующие подходы, опредемяющие поведения молодых специалистов на рынке труда. Елкина О. С. указывает «экономическое поведение на рынке труАа - это система Аействий по распреАелению имеющегося трудового потенциала человека с целью получения выгоды. Оно выражается в виде трудового поведения в его затратно-компенсационной форме. В качестве затрат выступают трудовые затраты, в качестве компенсации - доходы и субъективные выгоды. [1].

Как отмечает Щепкин О.Ю., «экономическое поведение молодежи на рынке труда преАставляет поиск каналов социальной мобильности, связанный со стремлением к успеху и самостоятельности. При этом признается противоречивый характер экономического поведения, Аетерминированность «возрастающими стремлениями», оАнако, причиной барьеров считаются сложность подготовки к профессиональным ролям и конфликт мичных целей и институциональных среАств трудоустройства и занятости» [6].

А.А. Константиновский определяет социальное поведение молодежи в отношении выбора тесно переплетенных межАу собой образовательной и профессиональной траекторий связано с рынком труаа. Сигналы рынка труда Аобираются Ао молодежи (или - Ао семей, что более правильно) не только с опозАанием, но и с искажениями, «шумами», что мешает молоАым мюАям верно сориентироваться в ситуации, узнать и осознать текущие и перспективные потребности рынка труаа, условия работы, размеры оплаты и проч. Работодатели предъявляют претензии к социальному поведению молодежи 


\section{ПОАИТИКА И ОБЩЕСТВО • 3 (135) • 2016}

(несоответствие профессиональных ориентаций потребностям рынка труаа, завышенные требования к оплате труда, несоответствующий производству уровень социализации, неудовлетворительное отношение к труду и Ар.) [3].

На наш взгляА, можно сформулировать опредемение экономического поведения на рынке труда.

Экономическое поведение на рынке труда - это тип экономического поведения, который связан с реализацией и развитием собственного капитала (индивидуального или организационного) путем нахождения оптимального соотношения издержек и прибыли и подразумевает субъективное восприятие заработной платы с учетом уровня реализации человеческого капитала, мотивационных установок, общекультурных и образовательных компетенций мичности.

Современная социология молодежи считает, что молодежь как одна из главных производительных сил обладает высоким трудовым потенциалом, социальной и трудовой мобимьностью, характеризуется энергичностью, быстрой обучаемостью, стремкением к инновациям, творческим мышиением [4].

Молодежь уходит от простого механического Авижения по схеме: учеба - работа - семья пенсия. Современные выпускники хотят быть и явмяются мобильными, гибкими, способными работать с информацией и решать глобальные проблемы. Но при всех позитивных тенденциях изменения поведения, молодежь не способна самостоятельно пройти профессиональную социализацию. В этом молодому поколению нужна помощь семьи, преподавателей, ВУЗа, государства и самих работодателей. Аанный факт наличия трудностей в трудоустройстве говорит о необходимости постоянных исследований и мониторинга молодежного рынка труда.

Экономическое поведение молодых специалистов на рынке труда различается в зависимости от региона. Региональные различия обосновываются разным уровнем жизни в Москве и регионах. Ожидаемая заработная плата московских студентов и выпускников в несколько раз выше, чем в регионах. При сравнении желаемой заработной платы, учитывая разный уровень жизни столицы и регионов, можно выявить слеАующее противоречие, рис. 1.
Как следует из рисунка 1, Аанные характеристики указывают на желание молодых специалистов получить после окончания обучения АохоА, превышающий АохоА их семей на оАного человека в месяц. К примеру, студент 4 курса ориентирован на получение дохода в 60 тысяч рублей в месяц при уровне 2015 года, при этом уровень Аохода его семьи составцяет 45 тысяч рублей в месяц. Из рисунка виАно, что собственные доходы у студентов появляются к 3 курсу обучения. Это означает, что на молодежном рынке труда у соискателей субъективное амбициозное желание покучать заработную плату выше, чем получают его собственные родители. С оАной стороны, очевиАно, что у молодых специалистов есть желание развиваться, делать карьеру. С Аругой стороны, это стремление получать большую заработную плату не соответствует их уровню поАготовки, как отмечают опрошенные эксперты.

Высшее образование становится нормой А^я современного человека, проживающего в мегапомисах, особенно это заметно в Москве. Образование явмяется фильтром, необходимым Аля выхода на квалифицированный рынок труда. Образование - это первоначальный, но не единственный сигнал, на основе, которого современный работодатель оценивает качество и стратегию квалификационного развития молодого соискателя.

Поступиение в ВУЗ - это выбор своего будущего, выбор своей профессии. Не смотря на трансформацию ценностей о высшем образовании, такое решение многими принимается единожды. И абитуриентам трудно сделать этот первый шаг, ответственность за свой выбор будет нести только сам студент. Именно на этом этапе начинается взаимодействие студента со своим будущим работодателям. Это естественно, принятие решение о профиле ВУЗа, это понимание сферы деятельности, в которой хотят работать студенты. Информация о том, с какими организациями сотрудничают институты - это еще один фактор, оказывающий влияние на принятие решения абитуриентами. Отношение студента к выбору работодателя будет схожим с выбором ВУЗа. Если молодой человек не хочет тратить много сил на учебу, в Аальнейшем он не захочет и тяжекую работу. Модель поведения соискателя на рынке труда основывается на том, как был сделан выбор института. Все 


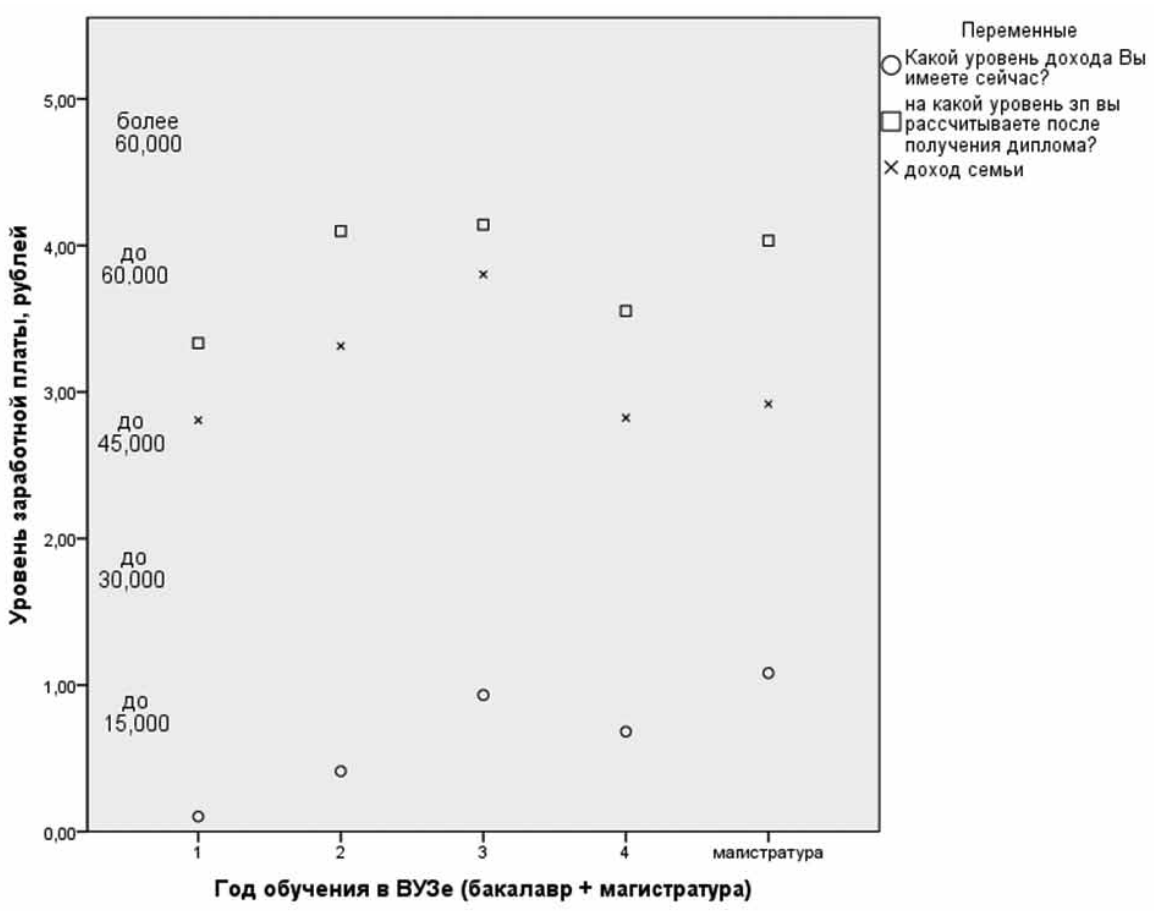

Рисунок 1. Сопоставление текущего и ожидаемого уровня дохода студентов в динамике по годам обучения

это классические примеры пересечения экономики и Аругих социальных факторов. Если включить поведенческие факторы, систематические ошибки в экономическую модель, то будет мегче понять то, как мюАи принимают решения. Кроме того, в отличие от большинства Аругих товаров и услуг, образование включает в себя опыт предыАущих покомений.

Работающий студент Аневного отАеления очной формы обучения - это объективная реальность, не учитывать которую немьзя. Около $28 \%$ студентов отметили, что их график позвомяет совмещать работу и учебу, 5\% отметили, что работают и часто пропускают занятия в ВУЗе. Аанное явление требует определенной регламентации и со стороны высшей школы, и со стороны работодателей, особенно в крупных субъектах Российской ФеАерации, гАе сосредоточено много ВУЗов. Разрешение ВУЗа на свободную посещаемость явцяется больше теоретическим понятием, чем практическим. Это обуславливает политику и еще раз подчеркивает значимость полного посещения мекционных и семинарских занятий. КажАый студент сам выбирает свою форму реализации своих профессиональных интересов. В следующей таблице 2 приведен каче- ственный анализ ответов стуАентов, почему они не хотят совмещать работу и учебу в ВУЗе.

Таблица 2

Качественный анамиз ответов респондентов. Почему стуАенты не хотят работать во время учебы?

\begin{tabular}{|c|c|}
\hline $\begin{array}{c}\text { Переменная } \\
\text { (вопрос иссле- } \\
\text { дования) }\end{array}$ & $\begin{array}{c}\text { Наиболее часто употребляемые } \\
\text { ответы респондентов (качествен- } \\
\text { ная интерпретация) }\end{array}$ \\
\hline $\begin{array}{l}\text { Почему сту- } \\
\text { денты не хотят } \\
\text { работать во } \\
\text { время учебы? }\end{array}$ & $\begin{array}{c}\text { «сложно совмещать работу } \\
\text { и учебу», «работа будет мешать уче- } \\
\text { бе», «хочу только учиться», «родите- } \\
\text { ли против», «учеба } \\
\text { в приоритете», «график учебы } \\
\text { не позволяет», «занимаюсь спор- } \\
\text { том», «не хватает времени», «нет } \\
\text { необходимости», «не разрешают } \\
\text { родители», «не хочу», «нет свобод- } \\
\text { ного времени» }\end{array}$ \\
\hline
\end{tabular}

Примечание: составлено автором по результатам анкетирования.

Студенты указывали, как собственное желание не работать во время обучения, так и запрет родителей. Чаще всего встречался ответ, когАа стуАент не имеет возможности совмещать работу и учебу. Амя многих учеба выходит на первый пиан. Из полученных Аанных можно саелать вывоА, что высшее образование явцяется сигналом на рын- 
Качественный анахиз ответов респондентов

\begin{tabular}{|c|c|}
\hline $\begin{array}{r}\text { Переменная (в } \\
\text { исследован }\end{array}$ & $\begin{array}{c}\text { Наиболее часто употребляемые ответы респондентов } \\
\text { (качественная интерпретация) }\end{array}$ \\
\hline $\begin{array}{c}\text { Какими знаниями и } \\
\text { навыками, на Ваш } \\
\text { взгляд, Вам необходи- } \\
\text { мо владеть, чтобы быть } \\
\text { конкурентоспособным } \\
\text { для работодателя? }\end{array}$ & $\begin{array}{c}\text { «адекватность», «активность», «аналитические знания», «англ.яз», «амбициозность», } \\
\text { «заинтересованность в получении работы», «высшее образование», «иностранные } \\
\text { языки», «высокая самоотдача», «высокий уровень подготовки», «гибкость», «грамот- } \\
\text { но писать и говорить», «желание работать и узнавать новое», «зависит от работо- } \\
\text { дателя», «законодательство», «знания компьютера», «умение работать в команде», } \\
\text { «знания своего дела», «знания по специальности», «коммуникабельность», «умение } \\
\text { работать в команде», «ориентация на результат», «инициативность», «трудолюбив», } \\
\text { «исполнительность», «ответственность», «организованность», «пунктуальность», } \\
\text { «информационные технологии», «компетентность», «креативность», «лидерские } \\
\text { качества», «опыт работы», «оперативность», «скорость», «самообучаемость», «тру- } \\
\text { долюбие», «умение на практике применять профессиональные навыки», «усердие», } \\
\text { «интерес к работе» }\end{array}$ \\
\hline
\end{tabular}

Примечание: составлено автором по результатам анкетирования.

ке труда. Покученное высшее образование - это проба профессионализма, ювелирный штамп, который остается с человеком на всю жизнь. Название института - это мицевая сторона, а покученные знания - это изнанка, гАе качество швов - это качество знаний, покученных в институте. От правильного выбора будет зависеть будущая профессиональная социализация выпускника,

В современных условиях довольно распространено, что первая работа не связана с покучаемым и полученным образованием, а потому профессионализм отступает на второй план, Аа и работа по специальности на первых порах требует все тех же непрофессиональных, но очень важных знаний и умений. Современного работодателя при работе со студентами больше интересует не его базовые навыки, которые были получены в институте, а дополнительные. Как правило, это отсутствие у молодых специалистов коммуникационных навыков и незначительные практические знания об организационном повеАении. Само устройство на работу начинается с вещей непрофессиональных, а коммуникационных, требующих навыков общения, умения преподнести себя, выдержки, стрессоустойчивости, т.е. всего того, чему чаще всего в ВУЗах не учат. В следующей таблице указано, какие качества молодые соискатели видят наиболее востребованными на рынке труда. Так же приводится качественный анализ ответов по компетенциям, которые молодые специалисты хотят развивать в ближайшие 2-3 года., табл. 3.
Задача исследования заключается в получении информации о наиболее значимых компетенциях Аля молодых специалистов, а также анализ самооценки студентов по предложенным компетенциям. Уровень самооценки респондентов преАставлен в табл. 4.

Таблица 4

Уровень самооценки респондентов

\begin{tabular}{|l|c|c|}
\hline \multicolumn{1}{|c|}{$\begin{array}{c}\text { Показатель } \\
\text { (оцениваемый } \\
\text { параметр) }\end{array}$} & $\begin{array}{c}\text { Сред- } \\
\text { нее }\end{array}$ & $\begin{array}{c}\text { Мода (наиболее } \\
\text { часто употреб- } \\
\text { ляемое значение) }\end{array}$ \\
\hline физическая подготовка & 3,78 & 4,00 \\
\hline $\begin{array}{l}\text { коммуникативные } \\
\text { качества }\end{array}$ & 4,03 & 4,00 \\
\hline $\begin{array}{l}\text { владение иностранными } \\
\text { языками }\end{array}$ & 3,18 & 3,00 \\
\hline $\begin{array}{l}\text { умение организовывать } \\
\text { свое время }\end{array}$ & 3,86 & 4,00 \\
\hline лидерские качества & 3,71 & 4,00 \\
\hline креативные качества & 3,77 & 4,00 \\
\hline $\begin{array}{l}\text { информационно-анали- } \\
\text { тические качества }\end{array}$ & 3,79 & 4,00 \\
\hline $\begin{array}{l}\text { ответственность, испол- } \\
\text { нительность }\end{array}$ & 4,34 & 5,00 \\
\hline $\begin{array}{l}\text { организаторские спо- } \\
\text { собности }\end{array}$ & 3,93 & 4,00 \\
\hline $\begin{array}{l}\text { презентационные } \\
\text { навыки }\end{array}$ & 3,72 & 4,00 \\
\hline эмоциональная & 3,92 & 4,00 \\
\hline
\end{tabular}

Примечание: составлено автором.

Из Аанной таблицЫ виАно, что молодые специалисты высоко оценивают свои компетенции. Сравнение Аанных самооценок с уровнем желаемой заработной платы преАставлено на рис. 2. 


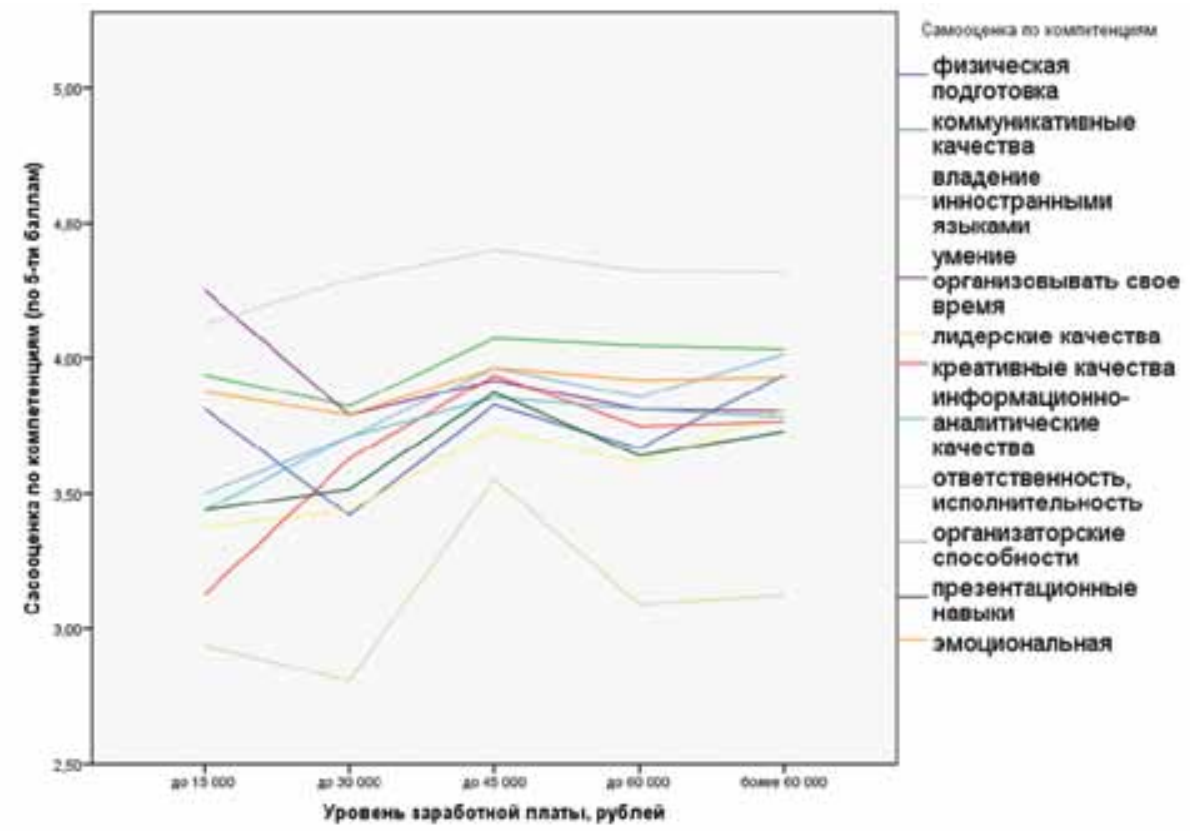

Рисунок 2. Взаимосвязь ожидаемого уровня заработной платы с самооценкой молодых специалистов по компетенциям

Как следует из Аанного рисунка, уровень ожидаемой заработной платы у молодых специалистов не увязан с их самооценкой по размичным компетенциям. Исключение может составмять такая компетенция как уровень вмадения иностранным языком. Это обусловмено низкой языковой поАготовкой в региональных ВУЗах, а так же отсутствием мотивации к изучению иностранных языков. Исходя из данного рисунка и проведенных эмпирических исследований в разных регионах страны, можно сдекать принципиальный вывоА о том, что экономическое поведение молодых специалистов недостаточно развито, так как ожидаемая заработная не зависит от реального уровня поАГотовки молоАЫх специалистов. Молодые соискатели испытывают трудности в объективной самооценке своих компетенций в сику завышения своих знаний. Выявленный уровень самооценки по компетенциям у молодых специалистов не различается существенным образом при ожидаемой заработной платы в 15000 руб. ими в 60000 руб. (в ценах 2015 года).
На основе проведенных эмпирических исслеАований было выявлено, что величина заработной платы влияет на степень использования человеческих ресурсов. Высокий уровень заработной платы явмяется оАной их самых важных позиций амя молодого соискатемя при выборе места работы. Высокое материальное вознаграждение стимулирует соискателей выбирать работу не по специальности, а с высоким материальным вознаграждением. Аеньги на рынке труда выступают большим соблазном, у соискателя уменьшается внутренняя мотивация и увеличивается внешняя. Практика проведенных исследований показывает, что такое поведение может быть крайне затруднительным и остается мишь преАполагаемой моделью поиска работы. По данным исследования, молодые специалисты в 2015 году в среАнем желают получать около 45 тыс. руб. в месяц, реальные доходы выпускников в рамках этого же исследования намного ниже. При этом отмечается, что уровень самооценки молодыми соискатемями своих компетенций не имеет размичия в зарплате в 15 тыс. рублей или 60 тыс. руб.

\section{БИБАИОГРАФИЯ}

1. Елкина О.С., Половинко В.С. Некоторые вопросы оценки стратегий экономического поведения человека на рынке труаа // Вестник Омского университета. 1999. Вып. 1. С. 100-103. 


\section{ПОАИТИКА И ОБЩЕСТВО • $3(135) \cdot 2016$}

2. Зимняя И.А. КАючевые компетенции новая парадигма результата образования / И.А. Зимняя // Высшее образование сегодня. 2003. № 5. С. 34-42.

3. Константиновский А.А., Вознесенская Е.А., Чередниченко Г.А. Молодежь России на рубеже XX-XXI веков: образование, труА, социальное самочувствие. М.: ЦСП и М, 2014. 548 с.

4. Аеньков Р.В. Социология молодежи: учебник Амя академического бакалавриата. М.: ИзА-во Юрайт, 2014. $416 \mathrm{c}$.

5. Потравная Е.В. Экономическое поведение социальных субъектов: экологический аспект // Горизонты экономики. 2014. № 6(18). С. 69-73.

6. Щепкин О.Ю. Экономическое поведение российской молодежи на рынке труда: автореф. Аис. кан. социоц. наук. Новочеркасск, 2006. 28 с.

7. David K. Brown The Social Sources of Educational Credentialism: Status Cultures, Labor Markets, and Organizations Sociology of Education Vol. 74, Extra Issue: Current of Thought: Sociology of Education at the Dawn of the 21st Century (2001), p. 19-34.

8. Economic Behavior // Donald W. McConnel, Edith Ayres, A. Anton Friedrich. Willard E. Atkins. Cambridge: The Riverside Press, $1939.923 \mathrm{p}$.

9. Rose, David C. The moral foundation of economic behavior. New York: Oxford University Press,2011.269 p.

10. Spence M. Job Market Signalling // Quarterly Journal of Economics. 1973. p. 355-374.

\section{REFERENCES}

1. Elkina O.S., Polovinko V.S. Nekotorye voprosy otsenki strategii ekonomicheskogo povedeniya cheloveka na rynke truda // Vestnik Omskogo universiteta. 1999. Vyp. 1. S. 100-103.

2. Zimnyaya I.A. Klyuchevye kompetentsii novaya paradigma rezul'tata obrazovaniya / I.A. Zimnyaya // Vysshee obrazovanie segodnya. 2003. № 5. S. 34-42.

3. Konstantinovskii D.L., Voznesenskaya E.D., Cherednichenko G.A. Molodezh' Rossii na rubezhe XXXXI vekov: obrazovanie, trud, sotsial'noe samochuvstvie. M.: TsSP i M, 2014. $548 \mathrm{s.}$

4. Len'kov R.V. Sotsiologiya molodezhi: uchebnik dlya akademicheskogo bakalavriata. M.: Izd-vo Yurait, 2014. $416 \mathrm{~s}$.

5. Potravnaya E.V. Ekonomicheskoe povedenie sotsial'nykh sub"ektov: ekologicheskii aspekt // Gorizonty ekonomiki. 2014. № 6(18). S. 69-73.

6. Shchepkin O.Yu. Ekonomicheskoe povedenie rossiiskoi molodezhi na rynke truda: avtoref. dis. kan. sotsiol. nauk. Novocherkassk, 2006. $28 \mathrm{~s}$.

7. David K. Brown The Social Sources of Educational Credentialism: Status Cultures, Labor Markets, and Organizations Sociology of Education Vol. 74, Extra Issue: Current of Thought: Sociology of Education at the Dawn of the 21st Century (2001), p. 19-34.

8. Economic Behavior // Donald W. McConnel, Edith Ayres, A. Anton Friedrich. Willard E. Atkins. Cambridge: The Riverside Press, $1939.923 \mathrm{p}$.

9. Rose, David C. The moral foundation of economic behavior. New York: Oxford University Press,2011.269 p.

10. Spence M. Job Market Signalling // Quarterly Journal of Economics. 1973. p. 355-374. 